\title{
Correction to: The Kinetics of Two-Step Ellagitannin Extraction from the By-Products of Selected Processed Fruits of the family Rosaceae
}

\author{
Agnieszka Milczarek ${ }^{1}$ (D) $\cdot$ Michał Sójka $^{1} \cdot$ Robert Klewicki $^{1}$
}

Published online: 24 February 2022

(c) The Author(s) 2022

\section{Correction to: Analytical Methods} https://doi.org/10.1007/s12161-021-02121-1

In this article the wrong figure appeared as Fig. 2.; the figure should have appeared as shown below.

The original article has been corrected.

Open Access This article is licensed under a Creative Commons Attribution 4.0 International License, which permits use, sharing, adaptation, distribution and reproduction in any medium or format, as long as you give appropriate credit to the original author(s) and the source,

provide a link to the Creative Commons licence, and indicate if changes were made. The images or other third party material in this article are included in the article's Creative Commons licence, unless indicated otherwise in a credit line to the material. If material is not included in the article's Creative Commons licence and your intended use is not permitted by statutory regulation or exceeds the permitted use, you will need to obtain permission directly from the copyright holder. To view a copy of this licence, visit http://creativecommons.org/licenses/by/4.0/.

Publisher's Note Springer Nature remains neutral with regard to jurisdictional claims in published maps and institutional affiliations.

The online version of the original article can be found at https:// doi.org/10.1007/s12161-021-02121-1

Agnieszka Milczarek

agnieszka.milczarek@p.lodz.pl

Michał Sójka

michal.sojka@p.lodz.pl

Robert Klewicki

robert.klewicki@p.lodz.pl

1 Institute of Food Technology and Analysis, Lodz University of Technology, ul. Stefanowskiego 4/10, 90-924 Lodz,

Poland 

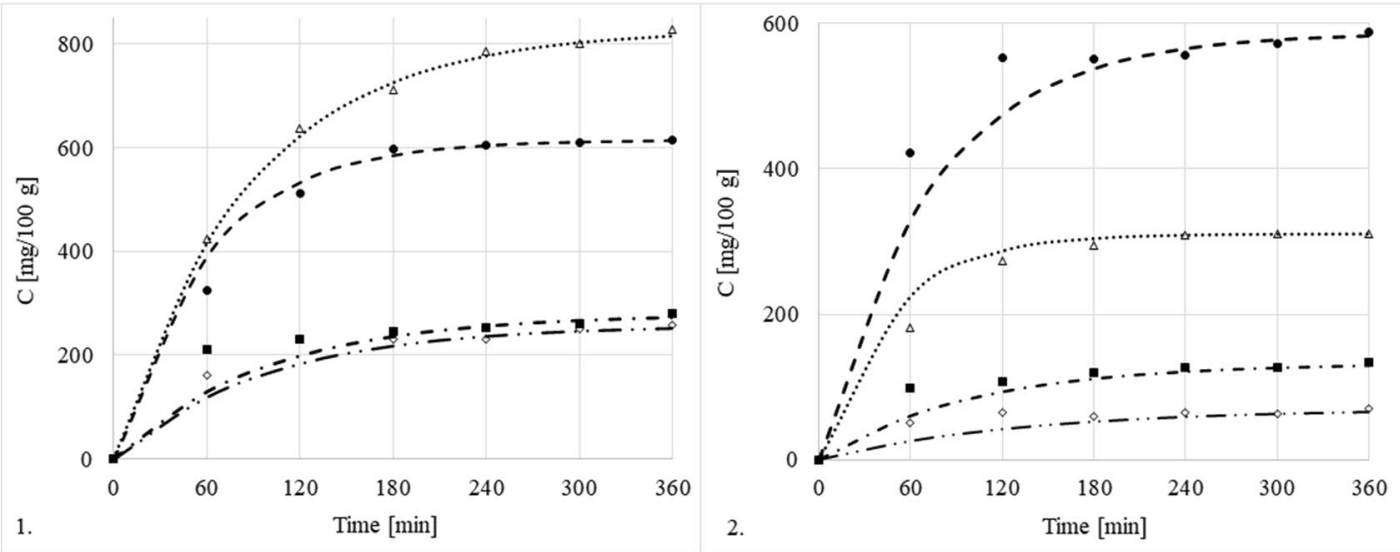

- Raspberry - Step 1

- Raspberry - Step 2

$\Delta$ Blackberry - Step 1

- Blackberry - Step 2

- 1 st order model Raspberry - Step 1

-. - 1st order model -

Raspberry - Step 2

......1st order model Blackberry - Step 1

- $\cdot$ 1st order model Blackberry - Step 2
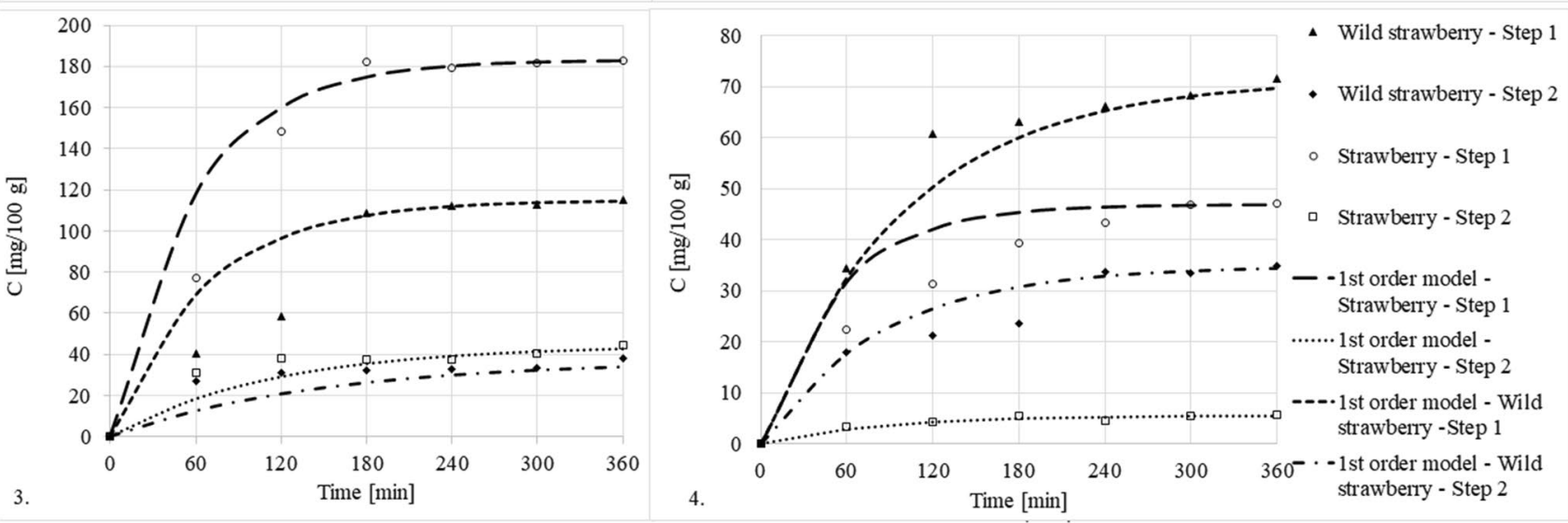